\title{
Vesicoureteral reflux in the early stage of spinal cord injury: a retrospective study
}

\author{
T Suzuki*,1 and T Ushiyama ${ }^{1}$ \\ ${ }^{1}$ Department of Urology, National Rehabilitation Center for the Disabled, Tokorozawa, Japan
}

\begin{abstract}
Study design: A retrospective study.
Objectives: To investigate the risk factors of vesicoureteral reflux in the early stage of spinal cord injury.

Setting: Japan.

Methods: Urological evaluation, including cystography and urodynamic study was performed in patients in the early stage of spinal cord injury. The patients were divided into two groups. Group 1 included 13 patients with vesicoureteral reflux. Group 2 included 97 patients without vesicoureteral reflux. We compared Group 1 and Group 2 regarding bladder deformation, the level of spinal cord injury, bladder behaviour, bladder compliance, high urethral closure pressure and method of urine evacuation.

Results: The patients injured between Th10 and L2 showed a significantly higher incidence of vesicoureteral reflux than those injured in other areas $(P<0.01)$. Furthermore, bladder compliance among patients with vesicoureteral reflux tended to be low. Other factors showed no differences between patients with and without vesicoureteral reflux.

Conclusion: Injuries between Th10 and L2 involve the sympathetic nervous system. Patients with such injuries often exhibited vesicoureteral reflux in the early stage of spinal cord injury. Spinal Cord (2001) 39, 23-25
\end{abstract}

Keywords: spinal cord injury; vesicoureteral reflux

\section{Introduction}

Neurogenic bladder in spinal cord injury may result in not only deformation of the bladder anatomy but also vesicoureteral reflux and upper tract deterioration. However, some patients show vesicoureteral reflux in the early stage of spinal cord injury. We investigated factors concerning vesicoureteral reflux by dividing our subjects into two groups, one with vesicoureteral reflux and the other without.

\section{Material and methods}

In patients with spinal cord injury, the development of neurogenic bladder is unavoidable. At our institution, patients with spinal cord injury admitted for rehabilitation routinely undergo intravenous urography, cystography, and urodynamic studies. We evaluated 110 patients with traumatic spinal cord injury who underwent a urological examination within 5 years after the acute injury. We divided the subjects into two groups, Group 1 included 13 patients with vesicoureteral reflux, Group 2 included 97 patients without vesicoureteral reflux as shown by cystography. Each group was

*Correspondence: T Suzuki, Department of Urology, National Rehabilitation Center for the Disabled, Namiki 4-1 Tokorozawa Saitama prefecture, Japan compared regarding deformation of the bladder, the level of spinal cord injury, bladder behaviour, bladder compliance, maximum urethral closure pressure and method of urine evacuation. The patients were further divided into two groups according to the level of spinal cord injury. Group A consisted of patients with spinal cord injury between Th10 and L2 which involves the sympathetic nervous system. ${ }^{1}$ Group B consisted of all other patients with spinal cord injury between $\mathrm{C} 4$ and Th9, and between L3 and L4. Deformation of the bladder was classified into four groups according to the degree of deformation: ${ }^{2}$ Grade 0 , circular $\sim$ elliptic bladder without trabeculation; Grade 1, circular elliptic bladder with slight trabeculation; Grade 2, distorted bladder (deviation from the circular elliptic shape) without marked trabeculation or circular elliptic bladder with marked trabeculation; and Grade 3, distorted bladder with marked trabeculation. The degree of vesicoureteral reflux was classified into five groups with reference to an international classification system. ${ }^{3}$

\section{Results}

The duration between acute injury and cystography of patients with vesicoureteral reflux averaged 13.0 \pm 9.0 
months. That of patients without vesicoureteral reflux was $12.5 \pm 15.9$ months. Deformation of the bladder mostly Grade 1 or Grade 2, and there was no significant difference between patients with and without vesicoureteral reflux (Table 1). With regard to the level of spinal cord injury, Group A included 23 patients with suspected injury to the lumbar sympathetic nervous system and showed a significantly higher incidence of vesicoureteral reflux than the 87 patients in Group B $(P<0.01)$ (Table 2). Of the 87 patients, six showed vesicoureteral reflux. The site of injury was C6 in two of the six patients, Th4 in two and Th5 and Th6 in one each. Of 11 patients with vesicoureteral reflux (two did not undergo cystometory), eight had an areflexic bladder, and of the 92 patients without vesicoureteral reflux who underwent cystometory, 57 had an areflexic bladder (Table 3). There was no significant difference between these groups. The average bladder compliance in patients with vesicoureteral reflux was $7.4 \pm 8.5 \mathrm{ml} / \mathrm{cmH}_{2} \mathrm{O}$, and in patients without vesicoureteral reflux it was $13.0 \pm 14.3 \mathrm{ml} / \mathrm{cmH}_{2} \mathrm{O}$.

Patients with vesicoureteral reflux showed slightly lower bladder compliance than those without. The

Table 1 Comparison using deformation of the bladder

\begin{tabular}{lcc}
\hline Grade & VUR $^{*}$ group & Non-VUR \\
\hline 0 & 0 & 8 roup \\
I & 7 & 46 \\
II & 5 & 42 \\
III & 1 & 1 \\
\hline
\end{tabular}

$* \mathrm{VUR}=$ vesicoureteral reflux

Table 2 Comparison using the level of spinal cord injury

\begin{tabular}{lccc}
\hline & $\begin{array}{c}\text { Th10-L2 } \\
\text { (Group A) }\end{array}$ & $\begin{array}{c}\text { Other levels } \\
\text { (Group B) }\end{array}$ & Total \\
\hline VUR* group & 7 & 6 & 13 \\
Non-VUR* group & 16 & 81 & 97 \\
Total & 23 & $87 \quad P<0.01$ & 110 \\
& \multicolumn{3}{c}{$P<$} \\
\hline
\end{tabular}

The 110 patients were classified into the VUR and non-VUR groups. The number of patients with spinal cord injury at Th10-L2 and that of patients with injury at the other levels (C4-Th9 or L3-L4) in each group are shown in the table, and the chi-square test was performed. $* \mathrm{VUR}=$ vesicoureteral reflux

Table 3 Comparison of bladder behaviour

\begin{tabular}{lcc}
\hline Bladder behaviour & VUR ${ }^{*}$ group & Non-VUR \\
\hline Areflexia & 8 & 57 \\
Hyperreflexia & 3 & 33 \\
Normal & 0 & 2 \\
Total & $11^{* *}$ & $92 \#$ \\
\hline *VUR = vesicoureteral & reflux. **Two did not undergo \\
cystometory; \#Five did not undergo cystometory
\end{tabular}

average maximum urethral closure pressure in patients with vesicoureteral reflux was $109.4 \pm 39.5 \mathrm{mmH}_{2} \mathrm{O}$ and in patients without vesicoureteral reflux it was $104.5 \pm 40.5 \mathrm{mmH}_{2} \mathrm{O}$. Degree of vesicoureteral reflux was not significantly different between Group A and Group B (Table 4). With regard to the method of urine evacuation, there was no significant difference between patients with and without vesicoureteral reflux (Table 5).

\section{Discussion}

Deterioration of the bladder wall from hypertrophy and fibrous tissue leads to ureterovesical junction changes which result in obstructive and refluxing physiologic patterns and affect bladder function. ${ }^{4} \mathrm{~A}$ functionally low compliant bladder, high urethral pressure and increased intravesical pressure are currently accepted as primary causes of upper urinary tract deterioration. ${ }^{5-7}$ However, vesicoureteral reflux (VUR) is also sometimes observed in patients early after spinal injury who show no marked vesical deformation, inflammation, trabeculae, or diverticula. Therefore the 110 patients who underwent urological examination within 5 years after the acute injury were divided into two groups based on cystographic findings, and each group was assessed regarding several factors. As a result, spinal cord injury patients who were injured between Th10 and L2, which involves the sympathetic nervous system, showed a significantly higher incidence of vesicoureteral reflux than patients who were injured in other spinal cord regions. Although there was no significant difference, the bladder compliance of patients with vesicoureteral reflux was slightly lower.

Table 4 Degree of vesicoureteral reflux (VUR) based on the level of spinal cord injury

\begin{tabular}{lcc}
\hline VUR & $\begin{array}{c}\text { Th10-L2 } \\
\text { (Group A) })\end{array}$ & $\begin{array}{c}\text { Other levels } \\
\text { (Group B) }\end{array}$ \\
\hline I & 2 & 2 \\
II & 3 & 3 \\
III & 2 & 0 \\
IV & 0 & 0 \\
V & 0 & 1
\end{tabular}

$* \mathrm{VUR}=$ vesicoureteral reflux

Table 5 Comparison of urinary evacuation between the two groups

\begin{tabular}{lcc}
\hline Method & VUR $^{*}$ group & Non-VUR \\
\hline Voluntary voiding & 1 & 12 \\
Involuntary voiding & 1 & 9 \\
Intermittent catheterization & 8 & 48 \\
Cystomy and indwelling & 3 & 28 \\
$\quad$ catheter & & \\
\hline
\end{tabular}

*VUR $=$ vesicoureteral reflux 
Deformation of the bladder and maximum urethral closure pressure were not found to be risk factors in the genesis of reflux. There have been some studies on the association between the sympathetic nerves and VUR. An experimental study in dogs has confirmed VUR after unilateral sympathectomy. ${ }^{8}$ However it is unlikely that the sympathetic nerves themselves actively control VUR. ${ }^{9}$ No development of VUR after sympathectomy has been reported. ${ }^{10}$ Kiruluta et $a l^{11}$ collected tissue of the detrusor muscle of the urinary bladder from puppies within 6 months after birth and suggested an association between decreased adrenergic fibres and increased incidence of VUR. Our findings suggest that in patients with a suspected injury to the lumbar sympathetic nervous system, a high incidence of reflux and low bladder compliance are very important factors concerning the neurogenic bladder and its treatment.

\section{References}

1 Tanago EA, Meyers FH. Trigonal hypertrophy, a cause of ureteral obstruction. J Urol 1965; 93: 678.
2 Ogawa T, Yosida T, Fujinaga T. Bladder deformity in traumatic spinal cord injury patients. Acta Urol Jap 1988; 34: 1173-1178.

3 Report of the international reflux study committee, Medical versus surgical treatment of primary vesicoureteral reflux: A prospective international reflux study in children. J Urol 1981; 125: 277.

4 Anderson RU. Urodynamic pattern after acute spinal cord injury: association with bladder trabeculation in male patients. $J$ Urol 1983; 129: 777.

5 Shinya K et al. Relevance of detrusor hyperreflexia, vesical compliance and urethral pressure to the occurrence of vesicoureteral reflux in myelodysplastic patients. J Urol 1992; 147: 413 415.

6 Ronald $\mathrm{G}$ et al. Risk factors for upper tract deterioration in chronic spinal cord injury patients. J Urol 1992; 147: 416-418.

7 Osamu Y et al. Morphological and functional factors predicting bladder deterioration after spinal cord injury. J Urol 1996; 155: 271.

8 Tanago EA, Huch JA, Meyers FH, Rambo ON. Primary vesicoureteral reflux. Experimental studies of its etiology. $J$ Urol 1965; 93: 165-176.

9 Arne Fryjordet, Jr. Sympathectomy and ureteral reflux. Scand J Urol Nephrol 1968; 2: 196-198.

10 Alan J Wein et al. The effect of acute chemical sympathectomy on the competence of the Canine Ureterovesical junction. Urol Res 1975; 3: $95-97$.

11 Kiruluta HG, Kathee Fraser, Linda Owen. The significance of the adrenergic nerves in the etiology of vesicoureteral reflux. $J$ Urol 1986; 136: $232-235$. 